\title{
Bitki Çaylarına Bal İlavesinin Total Antioksidan Kapasitesine Etkisi
}

\author{
Şükran ÖZDATLI, Hande SİPAHİ, Mohammad CHAREHSAZ, Ahmet AYDIN, Erdem YEŞILADA
}

\section{ÖZET}

Son yıllarda yürütülen bilimsel araştırmalar bitki çaylarının ve balın taşıdıkları antioksidan etkili bileşenlerin birçok akut ve kronik hastalıkların gelişme riskini azaltmaya yardımcı olabileceğini göstermektedir. Ancak bitki çaylarının içerisine tatlandirıci olarak bal ilave edilmesi ile antioksidan kapasitede ne gibi bir değişim olabileceği konusu aydınlığa kavuşmamıştır. Bu çalışmanın amacı, Türkiye'de satılan 9 farklı karışık veya saf bitki çay örneğinin total antioksidan kapasitesinin hem tek başlarına hem de çam balı veya çiçek balı ilavesinden sonra TOAK değerlerindeki olası değişimin tespit edilmesidir. Bir fincana eşdeğer $100 \mathrm{ml}$ çaydaki en yüksek TOAK değeri melisa, siyah çay ve beyaz çayda görülmüştür. Bunları sırasıyla yeşil çay $>$ adaçayı > ekinezya $>$ papatya $>$ zencefil $>$ h hlamur takip etmiştir. Bitki çaylarının antioksidan etkisinin hem çam hem de çiçek balı ilavesi ile paralel olarak arttığ $1,7 \mathrm{~g}$ bal ilavesinin $3 \mathrm{~g}$ bala göre daha yüksek etkinlik gösterdiği gözlemlenmiştir. Bazı bitki çaylarında (melisa, adaçayı, ıhlamur, papatya, limonlu zencefil) çam balı ilavesinin çiçek balına oranla antioksidan etkinin daha fazla yükseldiği görülürken, bazılarında (ekinezya) çiçek balı ilavesinin daha etkili olduğu tespit edilmiştir. Sonuç olarak, çalışmamızda bitki çaylarına bal ilavesinin antioksidan aktiviteyi önemli ölçüde artırdığı ve günde en az 1 defa ballı çay içmenin vücudu serbest radikallere karşı koruyucu etki gösterebileceği ve özellikle oksidatif strese bağlı gelişen hastalıklarda destekleyici tedavi olarak kullanılabileceği düşünülmektedir. Ancak bu kombinasyonunun koruyucu mekanizmasının anlaşılması için ileri/ek çalışmalar gerekmektedir.

Anahtar Kelimeler: Bitki çayı, çiçek balı, çam balı, Total antioksidan kapasite (TOAK)
Şükran Özdatlı, Hande Sipahi, Mohammad Charehsaz, Ahmet Aydın Yeditepe Üniversitesi, Eczacllık Fakültesi, Toksikoloji Anabilim Dall, Istanbul, Türkiye.

Erdem Yeşilada

Yeditepe Üniversitesi, Eczacllık Fakültesi, Farmakognozi ve Fitoterapi Anabilim Dal, İstanbul, Türkiye.

\section{Sorumlu yazar:}

Dr. Hande Sipahi

Yeditepe Üniversitesi, Eczacılık Fakültesi, Toksikoloji Anabilim Dalı, 26 Ağustos Yerleşimi, Kayışdağı, İstanbul 34755, Türkiye

Tel: +90 2165780558

Faks: +90 2165780068

E-mail: handesipahi@hotmail.com

\section{GİRIŞ}

Bitkilerin kurutulmuş yaprak, çiçek, kabuk, meyve, tohum gibi toprak üstü kısımları ya da kök, rizom, yumru gibi toprak altı kısımlarından sıcak su içerisinde demlenerek (infüzyon) ya da kaynatılarak (dekoksiyon) hazırlanan bitki çayları en eski ilaç şekli olarak binlerce yıldır insan sağlığının korunması ve hastalıkların tedavisinde önemli rol oynamıştır (1). Ancak bitki çaylarının son yıllarda yürütülen bilimsel araştırmalar ile ortaya konulan biyolojik etkileri günümüzde bitki çaylarına olan ilgi ve talebi artırmıştır. Özellikle bitki çaylarının taşıdıkları antioksidan etkili bileşenlerin birçok akut ve kronik hastalıkların gelişme riskini azaltmaya yardımcı olabileceği bildirilmektedir (1-3).

Normal hücre aktiviteleri ve/veya ksenobiyotiklerin maruziyeti sonucunda oluşan serbest radikaller hücre membranını, DNA ve RNA gibi genetik materyali ve değişik enzimatik olayları etkileyerek hücre hasarına neden 
olmaktadır. Bu serbest radikaller vücudumuzda sitoplazmik, mitokondriyal ve ekstraselüler antioksidan enzim sistemleri tarafından etkisiz hale getirilmektedir (4). Ancak vücudun mevcut antioksidan sistemi yetersiz kaldığında oluşan bu serbest radikaller oksidatif hasara yol açarak kardiyovasküler hastalıklara, inflamasyona ve kanser oluşumuna kadar giden çeşitli hastalıklara yol açabilmektedir. Bu bakımdan dışarıdan yapılacak antioksidan desteğinin, oksidatif stresle baş etmede yardımcı olabileceği bildirilmektedir $(4,5)$.

Gerek bitki çayları ve gerekse balın antioksidan aktivitesi yürütülen bazı bilimsel araştırmalar ile gösterilmiştir $(6,7)$. Ancak bitki çayları içerisine tatlandırıcı olarak çiçek ve çam balı ilave edilmesi ile antioksidan kapasitede ne gibi bir değişim olabileceği konusu araştırılmamıştır.

Bu çalışmanın amacı, Türkiye'de satılan 9 farklı karışık veya saf bitki çayı örneğinin total antioksidan kapasitesinin (TOAK) tespiti ve bu çay örneklerine çiçek ve çam ballarının ilave edilmesi ile TOAK değerlerindeki olası değişimin tespit edilmesidir.

\section{GEREÇ VE YÖNTEM}

\section{Numune Hazırlanması}

Çalışmada kullanılan bitki çayları ve balların paket içeriği Tablo 1'de gösterilmektedir. Araştırmada Doğadan ${ }^{\circledR}$ marka bitki çayları ve Balparmak ${ }^{\circledR}$ marka çiçek balı ve çam balı kullanılmıştır. Örnekler analiz yapılana kadar orijinal ambalajlarında, karanlık ve serin laboratuvar ortamında muhafaza edilmiştir. Her bir bitki çayından rastgele 5 poşet alınarak üzerine $500 \mathrm{ml}$ taze olarak kaynatılmış su eklendikten sonra 5 dakika süreyle demlemeye bırakılmıştır. Demlenen stok çay örneğinden $100 \mathrm{~mL}$ 'lik porsiyonlar beherlere aktarılarak: çay, çay+3 g çiçek balı, çay+7 g çiçek balı, çay+3 g çam balı, çay+7 g çam balı olacak şekilde 5 gruba ayrılmıştır (Şekil 1). [3 $\mathrm{g}$ bal bir çay kaşığı; $7 \mathrm{~g}$ bal bir tatlı kaşığına eşdeğerdir]. Bütün örnekler $-20^{\circ} \mathrm{C}$ de 24 saat dondurulduktan sonra liyofilize edilerek (Christ Alpha 1-4 LSC Freeze-Dryer) kurutulmuş ve liyofilizatlar analiz yapılana kadar $+4^{\circ} \mathrm{C}$ de buzdolabında saklanmışırır.

Tablo 1: Çalışmada kullanılan bitki çaylarıve balların paket içeriği ve TOAK değerleri

\begin{tabular}{|c|c|c|c|c|c|}
\hline No & Bitki çayı /Bal & Paket içeriği & $\begin{array}{l}\text { Poşet başına } \\
\text { numune miktarı } \\
\text { (g) }\end{array}$ & $\begin{array}{l}\text { Üretim tarihi ve } \\
\text { Lot numarası }\end{array}$ & $\begin{array}{l}\text { TOAK* } \\
\text { (mg AAE/g kuru } \\
\text { ekstrakt) }\end{array}$ \\
\hline 1 & Melisa & Melisa, rezene, kıvırcık nane, anason & 1,5 & $\begin{array}{l}02 / 2013 \\
\text { L } 017\end{array}$ & 208,65 \\
\hline 2 & Adaçayı & Adaçayı & 1,3 & $\begin{array}{l}\text { 05/2013 } \\
\text { L } 075\end{array}$ & 165,25 \\
\hline 3 & Ekinezya & $\begin{array}{l}\text { Ekinezya otu (\%15), ekinezya kökü (\%15), tarçın, böğürtlen, } \\
\text { thlamur, Rooibos, karanfil, elma, adaçayı, limon kabuğu, } \\
\text { portakal kabuğu, zerdeçal, stevya, karabiber }\end{array}$ & 2 & $\begin{array}{l}\text { 02/2013 } \\
\text { L } 006\end{array}$ & 135,66 \\
\hline 4 & Ihlamur & Ihlamur, Rooibos, karanfil, tarçın & 1,6 & $\begin{array}{l}03 / 2013 \\
\text { L } 089\end{array}$ & 186,75 \\
\hline 5 & Papatya & Papatya & 1,5 & $\begin{array}{l}05 / 2013 \\
\text { L } 166\end{array}$ & 114,23 \\
\hline 6 & Yeşil çay & Yeşil çay & 1,75 & $\begin{array}{c}05 / 2013 \\
\text { L } 230\end{array}$ & 202,99 \\
\hline 7 & $\begin{array}{l}\text { Zencefil, limon } \\
\text { kabuğu }\end{array}$ & $\begin{array}{l}\text { Limon otu, zencefil (\%25), bamya, limon kabuğu(\%5,5) } \\
\text { zerdeçal, stevya, hindiba }\end{array}$ & 2 & $\begin{array}{l}\text { 04/2013 } \\
\text { L } 075\end{array}$ & 60,33 \\
\hline 8 & Siyah çay & Siyah çay & 2 & $\begin{array}{l}06 / 2013 \\
\text { L } 13060\end{array}$ & 132,90 \\
\hline 9 & $\begin{array}{l}\text { Beyaz çay, portakal } \\
\text { çiçeği }\end{array}$ & Beyaz çay, yeşil çay, portakal çiçeği $(\% 0,63)$, limon kabuğu & 1,75 & $\begin{array}{l}01 / 2013 \\
\mathrm{~L} 010\end{array}$ & 160,64 \\
\hline 10 & Çiçek balı & $\begin{array}{l}\text { Ağırlıklı olarak Doğu ve Güneydoğu Anadolu'nun kır } \\
\text { çiçeklerinden elde edilen ballardan derlenmiştir }\end{array}$ & $600 \mathrm{~g}$ & $\begin{array}{c}\text { 10/2013, } \\
\text { BPC13.0112 }\end{array}$ & $98,28 * *$ \\
\hline 11 & Çam balı & $\begin{array}{l}\text { Ağırlıklı olarak Yerkesik ve Marmaris yörelerinden elde } \\
\text { edilen ballardan derlenmiştir. }\end{array}$ & $600 \mathrm{~g}$ & $\begin{array}{c}\text { 09/2013, } \\
\text { BPM13.0070 }\end{array}$ & $116,39 * *$ \\
\hline
\end{tabular}

* Sonuçlar iki ölçümün ortalaması olarak verilmiştir.

** Tek ölçüm sonuçlarıdır 


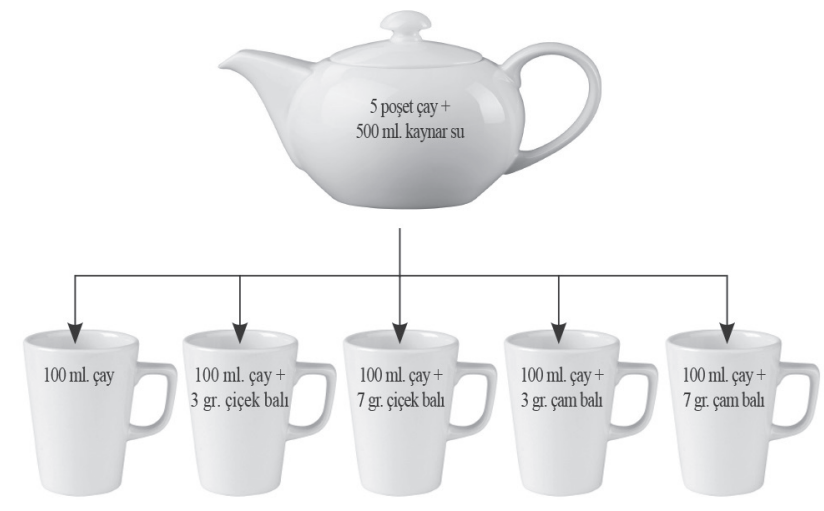

Şekil 1. Çay örneklerinin hazırlanması: Analizi standardize etmek için 5 poşet çay $500 \mathrm{ml}$ kaynar su ile 5 dakika demlendikten sonra, 100 ml'lik 5 porsiyona ayrılarak analizler gerçekleştirilmiştir.

\section{Total Antioksidan Kapasite Analizi}

Örneklerin total antioksidan kapasitelerinin TOAK değerlerinin belirlenmesi için fosfomolibden metodu kullanılmıştır (8). Deney antioksidan bileşiklerin Mo(VI)'y1 $\mathrm{Mo}(\mathrm{V})$ 'e indirgemesine ve sonuç olarak asidik ortamda yeşil fosfomolibdat kompleksine dönüşmesi esasına dayanmaktadır. $28 \mathrm{mM}$ sodyum fosfat monobazik (Riedel de Haen, Germany), 4 mM amonyum molibdat (Riedel de Haen, Germany), 0,6 M sülfürik asit (Sigma Co, USA) karıştırılarak reaktif solüsyon oluşturulmuştur. Bu reaktif solüsyondan $3 \mathrm{ml}$ alınarak $0,3 \mathrm{ml}$ uygun şekilde seyreltilmiş numune ile karıştırılarak $95{ }^{\circ} \mathrm{C}$ de $90 \mathrm{dk}$ inkübe edilmiştir. İnkübasyondan sonra numuneler oda sıcaklığında soğutularak absorbansları $695 \mathrm{~nm}$ 'de spektrofotometre (Thermoscientific evaluation 300, USA) ile ölçülmüştür. Askorbik asitten (Sigma Co, USA) 12,5, 25, 50, 100, 200 $\mu \mathrm{g} / \mathrm{mL}$ konsantrasyonlarında çalışma standartları hazırlanarak sonuçlar kuru ekstrakt gram ağırlığı başına askorbik asit eşdeğeri (AAE) (mg) olarak verilmiştir. Ayrıca sonuçlar, bitki çaylarının gerçek kullanım şartlarındaki total antioksidan kapasitelerinin değerlendirilebilmesi için 100 $\mathrm{ml}$ olarak kabul edilen bir fincan çayın total antioksidan kapasitesi olarak verilmiştir. Analizler ikişer defa tekrarlanmış ve sonuçlar iki ölçümün ortalaması olarak verilmiştir.

\section{BULGULAR}

Bitki çayı ekstraktlarının TOAK değerleri [mg AAE/g kuru ekstrakt] Tablo 1'de verilmiştir. Buna göre en yüksek total antioksidan kapasite melisa ve yeşil çay örneklerinde görülürken, diğer çayların antioksidan kapasitesi büyükten küçüğe ıhlamur> adaçayı $>$ beyaz çay> ekinezya> siyah çay $>$ papatya $>$ zencefil şeklinde sıralanmıştır.

Bal ilavesinin bitki çayı ekstraktlarının TOAK değerlerine etkisi (mg AAE/100ml) Şekil 2'de gösterilmiştir. Bal ilavesinin antioksidan aktivite üzerinde önemli düzeyde artışa neden olduğu görülmüştür. Ayrıca $3 \mathrm{~g}$ çiçek balı ilavesinde en yüksek antioksidan aktivite ekinezya ve siyah çayda görülürken; $7 \mathrm{~g}$ çiçek balı ilavesinde en yüksek aktivite melisa ve yeşil çayda görülmüştür. $3 \mathrm{~g}$ ve $7 \mathrm{~g}$ çam balı ilave edildiğinde ise en yüksek antioksidan aktivite melisa çayında görülmüşsür (Şekil 2).

(a)

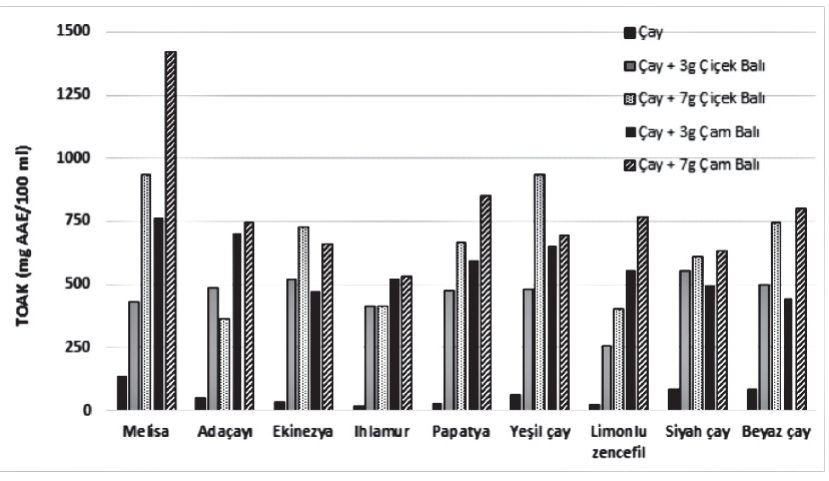

(b)

\begin{tabular}{lccccc}
\hline & \multicolumn{5}{c}{ TOAK (mg AAE $/ \mathbf{1 0 0}$ ml)* } \\
\hline & Çay & $\begin{array}{c}\text { Çay }+ \\
\text { 3g Çiçek } \\
\text { Balı }\end{array}$ & $\begin{array}{c}\text { Çay }+ \\
\text { 7g Çiçek } \\
\text { Balı }\end{array}$ & $\begin{array}{c}\text { Çay + } \\
\text { 3g Çam } \\
\text { Balı }\end{array}$ & $\begin{array}{c}\text { Çay + } \\
\text { 7g Çam } \\
\text { Balı }\end{array}$ \\
\hline Melisa & 137,06 & 430,14 & 936,51 & 761,81 & 1423,29 \\
Adaçayı & 52,44 & 484,27 & 363,45 & 701,87 & 744,77 \\
Ekinezya & 31,69 & 521,95 & 728,53 & 471,20 & 658,17 \\
Ihlamur & 18,63 & 413,78 & 412,27 & 524,98 & 533,84 \\
Papatya & 26,70 & 473,37 & 664,03 & 597,85 & 849,24 \\
Yeşil Çay & 59,57 & 479,88 & 935,38 & 651,29 & 695,41 \\
Limonlu & 21,67 & 258,73 & 400,68 & 555,66 & 764,72 \\
zencefil & & & & & \\
Siyah Çay & 86,59 & 551,24 & 610,65 & 496,16 & 629,79 \\
Beyaz Çay & 85,97 & 499,17 & 745,06 & 442,90 & 797,98 \\
\hline
\end{tabular}

*Sonuçlar iki ölçümün ortalaması olarak verilmiştir.

Şekil 2b. Bal ilavesi ile bitki çayı ekstraktlarının TOAK değerlerindeki değişim (mg AAE/100 ml) (a) grafik değerleri; (b) numerik değerler

\section{TARTIŞMA}

Yürütülen bilimsel araştırmalar balın eşsiz bir besin kaynağ 1 olmasının yanı sıra insan sağlığı bakımından önemli birçok 
biyolojik etkiye sahip olduğunu da ortaya koymaktadır; antimikrobiyal (bakteri, fungus, virüs, parazitler), antienflamatuvar, antihepatotoksik, antioksidan ve antitümör $(9,10)$. Özellikle balın antioksidan etkisine yönelik çok sayıda araştırma bulunmaktadır (11-17).

Dünyada en çok tüketilen içeceklerden biri olan bitki çayı sağlık üzerindeki olumlu etkilerinden dolayı yüzyıllardır geleneksel tedavilerde kullanılmaktadır. Yürütülen bilimsel araştırmalar bitki çaylarının insan sağlığının korunması ve hastalıkların tedavisinde etkinliğini ortaya koymaktadır. Çayların bu etkileri yapılarında bulunan antioksidan bileşenlerle ilişkilendirilmektedir (18-21). Çayların antioksidan aktiviteleri yapılarındaki farklı bileşenler nedeniyle genel olarak standart referans antioksidanlar ile karşılaştırılarak değerlendirilmektedir $(6,7)$. Bitkilerin antioksidan aktivite kapasiteleri, uygulanan ekstraksiyon yöntemine ve analitik yönteme göre değişkenlik göstermektedir $(8,22)$. Demleme sıcaklığının çayın antioksidan aktivitesi üzerine etkisinin incelendiği bir çalışmada, $70^{\circ}, 80^{\circ}, 90^{\circ}$ ve $100^{\circ} \mathrm{C}$ ile karşılaştırıldığında en yüksek antioksidan aktivitenin $80^{\circ} \mathrm{C}^{\prime}$ de gözlendiği bildirilmiştir (23).

Çalışmamızda poşet çayın ekstraksiyonu, genel olarak önerildiği şekilde, taze kaynatılmış sıcak su içerisinde 5 dakika demlenerek gerçekleştirilmiştir. TOAK askorbik asit yöntemine göre yapıldığında bir fincana eşdeğer $100 \mathrm{ml}$ çaydaki en yüksek TOAK değeri melisa, siyah çay ve beyaz çayda görülmüştür. Bunları sırasıyla yeşil çay $>$ adaçayı > ekinezya $>$ papatya $>$ zencefil $>$ hhlamur takip etmiştir. Kesic ve arkadaşlarının 14 farklı bitki ile yaptığı çalışmada da en yüksek antioksidan aktivitenin melisa çayında görüldüğü bildirilmektedir (24). Benzer bir sonuç Rusaczonek ve arkadaşları tarafından da gözlemlenmiş, incelenen çaylar içerisinde yeşil çay, beyaz çay ve siyah çayın en yüksek antioksidan aktiviteyi gösterdiği, ancak melisa çayının etkisinin bu çaylardan daha düşük olduğu tespit edilmiştir (25). Söz konusu bu çalışmaların sonuçları sadece melisa çayının antioksidan kapasitesi ile ilgili sonuçları yansıtmaktadır. Hâlbuki çalışmamızda en yüksek TOAK değerine sahip olduğu belirlenen melisa çayı içerisinde, melisanın yanı sıra kıvırcık nane, rezene ve anason da bulunmaktadir (Tablo 1). Dolayısıyla, etkileri değerlendirirken içerisindeki diğer bileşenlerin katkıları da göz önüne alınmalıdır. Diğer taraftan 100 ml'lik bir fincan çaya melisa tarafindan sağlanan toplam antioksidan aktivitesi yeşil çaydan fazla gözükse de her iki çaydan elde edilen ekstrelerin gramı başına aktiviteleri hesaplandığında iki çayın aktivitesinin birbirine çok yakın olduğu görülmektedir.
Bal ilavesinin bitki çaylarının antioksidan aktivitesi üzerine etkisi ile ilgili sınırlı sayıda çalışma mevcuttur. 14 farklı çaya farklı kaynaklı balların eklenmesinin genel olarak çayların antioksidan etkisini artırdığı, ancak bu artışın balın elde edildiği bitkiye göre farklılık gösterdiği bildirilmektedir (24). Diğer bir çalışmada ise siyah çaya farklı kaynaklı balların ilavesi ile antioksidan aktivitenin $\operatorname{art} \breve{g}_{1}$ gözlemlenmiştir (26).

Çalışmamızda hem çam hem de çiçek balı ilavesinin antioksidan kapasiteyi önemli seviyede arttırdığı tespit edilmiştir (Şekil 2). Genel olarak bitki çaylarının antioksidan etkisinin ilave edilen bal miktarı ile paralel olarak arttığı, $7 \mathrm{~g}$ bal ilavesinin $3 \mathrm{~g}$ bala göre daha yüksek etkinlik gösterdiği gözlemlenmiştir. Bal türlerinin etkisi kıyaslandığında, bazı bitki çayı örneklerinde (melisa, adaçayı, ıhlamur, papatya, limonlu zencefil) çam balı ilavesinin çiçek balına oranla antioksidan etkiyi daha fazla yükselttiği görülürken, ekinezya çayında çiçek balı ilavesinin daha etkili olduğu tespit edilmiştir. Çay bitkisi (Camellia sinensis) yapraklarından farklı şekillerde hazırlanan beyaz ve siyah çaya $3 \mathrm{~g}$ çiçek balı ilavesinin çam balı ilavesine göre daha yüksek antioksidan etki gösterdiği görülmektedir. Diğer taraftan, çiçek balının $7 \mathrm{~g}$ ilave edilmesi ile aktivite beklendiği şekilde artış göstermemiştir. Bu durumun muhtemelen bal bileşenleri ile çay bileşenleri arasındaki etkileşime bağlı olduğu düşünülmektedir.

Ayrıca, ıhlamur, limon/zencefil çayı gibi özellikle üst solunum yolu şikâyetlerinde tedaviye yardımcı olarak sıklıkla uygulanan bitki çaylarının antioksidan etkilerinin düşük olmasına karşılık, içerisine bal ilavesi ile antioksidan kapasitelerindeki artış dikkat çekicidir. Balın üst solunum yolu şikâyetlerinde bilinen etkinliği ile birlikte değerlendirildiğinde TOAK değerinde gözlenen bu artış önemli bir avantaj olarak değerlendirilebilir (27).

Sonuç olarak, çalışmamızda bitki çaylarına bal ilavesinin antioksidan aktiviteyi önemli ölçüde artırdığı ve günde en az bir defa ballı çay içmenin vücudun serbest radikallere karşı koruyucu etki gösterebileceği ve özellikle oksidatif strese bağlı gelişen hastalıklarda destekleyici tedavi olarak kullanılabileceği düşünülmektedir. Ancak bu çalışmada kullanılan bitki çayı örneklerinin, adaçayı, siyah ve yeşil çay ve papatya hariç, birer karışım olduğu göz önüne alınması, sonuçların bu bakımdan değerlendirilmesi doğru olacaktır. Ayrıca poşet çay ve bal kombinasyonunun koruyucu mekanizmasının anlaşılması için ayrıntılı çalışmalar yapılması gerekmektedir. 


\section{Effect of Honey Supplementation on Total Antioxidant Capacity of Herbal Teas}

\section{ABSTRACT}

Scientific researchers have revealed that antioxidant components in herbal teas and honey would be beneficial for the health and may help to reduce the risk of development of acute and chronic diseases. However, possible changes in the antioxidant capacity of herbal teas by the addition of honey as a sweetener have not been investigated in detail yet. The aim of this study was to determine the total antioxidant capacity (TOAC) of 9 different mixed or pure herbal teas marketed in Turkey and then possible changes in the TOAC value of these tea samples after addition of either flower or pine honey. For $100 \mathrm{ml}$ tea which is equivalent to a cup of tea, the highest TOAC value was observed in melissa, black tea and white tea and these were followed by green tea $>$ sage $>$ echinacea $>$ daisy $>$ ginger $>$ linden, respectively. The antioxidant activity of these tea samples increased by the addition of both flowers and pine honeys and $7 \mathrm{~g}$ of honey exerted higher activity than $3 \mathrm{~g}$ of honey. Higher antioxidant activity was observed in some herbal tea samples (melissa, sage, linden, chamomile, lemon ginger) by the addition of pine honey, whereas in some teas (echinacea, black, white and green teas) flower honey supplementation has been found to be more effective. In conclusion, our study suggests that addition of honey to herbal tea increase its antioxidant activity significantly and drinking herbal tea with honey at least once a day may protect the body against the harmful effects of free radicals. However, further studies are required to understand the protective mechanisms of this combination.

Key words: Herbal teas, flower honey, pine honey, total antioxidant capacity (TOAC)

\section{KAYNAKLAR}

1. Piljac-Zegarac J, Samec D, Piljac A. Herbal teas: A focus on antioxidant properties. In: Tea in Health and Diseases Prevention. Section 2: Miscellaneous Teas and Tea Types: Non-Camellia sinensis. Editor: Victor Preedy, Inc. Academic Press. 2013, pp.129-140.

2. Craig WJ. Health- properties of common herbs. Am J Clin Nutr 1999; 70(suppl): 491S-9S.

3. Dufresne CJ, Farnworth ER. A review of latest research findings on the health promotion properties of tea. J Nutr Biochem 2001; 12 : 404-21.

4. Aydın A, Sayal A, Isımer A. Serbest radikaller ve antioksidan savunma sistemi. Gülhane Askeri Tıp Akademisi Ayın Kitabı, Ankara. 2001.

5. Selvaraju V, Joshi M, Suresh S, Sanchez JA, Maulik N, Maulik G. Diabetes, oxidative stress, molecular mechanism, and cardiovascular disease-an overview. Toxicol Mech Methods 2012; 22: 330-35.

6. Küçük M, Kolaylı S, Karaoğlu Ş, Ulusoy E, Baltacı C, Candan F. Biological activities and chemical composition of three honeys of different types from Anatolia. Food Chem 2007; 100: 526-34.

7. Atoui AK, Mansouri A, Boskou G, Kefalas P. Tea and herbal infusions: Their antioxidant activity and phenolic profile. Food Chem 2005; 89: 27-36.

8. Celep E, Aydın A, Kırmızıbekmez H, Yesilada E. Appraisal of in vitro and in vivo antioxidant activity potential of cornelian cherry leaves. Food Chem Toxicol 2013; 62: 448-55.

9. Bogdanov S, Jurendic T, Sieber R, Gallmann P. Honey for nutrition and health: a review. J Am Coll Nutr 2008; 27: 677-89.

10. Eteraf-Oskouei T, Najafi M. Traditional and modern uses of natural honey in human diseases: A review. Iran J Basic Med Sci 2013; 16: $731-42$.

11. Aazza S, Lyoussi B, Antunes D, Miguel MG. Physicochemical characterization and antioxidant activity of 17 commercial Portuguese honeys. J Food Sci 2013; 78: 1159-65.

12. Moniruzzaman M, Khalil MI, Sulaiman SA, Gan SH. Advances in the analytical methods for determining the antioxidant properties of honey: a review. Afr J Tradit Complement Altern Med 2011; 9: $36-42$.

13. Gašić $\mathrm{U}$, Kečkeš $\mathrm{S}$, Dabić D, Trifković J, Milojković-Opsenica D, Natić M, Tešić Z. Phenolic profile and antioxidant activity of Serbian polyfloral honeys. Food Chem 2014; 15: 599-607.

14. Akbulut M, Ozcan MM, Coklar H. Evaluation of antioxidant activity, phenolic, mineral contents and some physicochemical properties of several pine honeys collected from Western Anatolia. Int J Food Sci Nutr 2009; 60: 577-89.

15. Piljac-Zegarac J, Samec D, Piljac A, Mesić A, Tkalcec Z. Antioxidant properties and phenolic content of different floral origin honeys. JAAS 2009; 1: 43-50.

16. Pontis JA, Costa LAMA, Silva SJR, Flach A. Color, phenolic and flavonoid content, and antioxidant activity of honey from Roraima, Brazil. Food Sci Technol (Campinas) 34: 69-73.

17. Almaraz-Abarca N, Campos MG, Ávila-Reyes JA, Naranjo-Jiménez N, Corral JH, González-Valdez LS. Antioxidant activity of polyphenolic extract of monofloral honeybee-collected pollen from mesquite (Prosopis juliflora, Leguminosae). J Food Compost Anal 2007; 20: 119-24.

18. Alok S, Jain SK, Verma A, Kumar M, Mahor A, Sabharwal M. Herbal antioxidant in clinical practice: a review. Asian Pac J Trop Biomed 2014; 4:78-84.

19. Costa ASG, Nunes MA, Almeida IMC, Carvalho MR, Barroso MF, Alves RC, Oliveira MBPP. Teas, dietary supplements and fruit juices: A comparative study regarding antioxidant activity and bioactive compounds. LWT - Food Sci Technol 2012; 49: 324-8.

20. Chrpová D, Kouřimská L, Gordon MH, Heřmanová V, Roubičková I, Pánek J. Antioxidant Activity of Selected Phenols and Herbs Used in Diets for Medical Conditions. Czech J Food Sci 2010; 28:317-25.

21. Derakhshani Z, Hassani A, Pirzad A, Abdollahi R, Dalkani M. Evaluation of phenolic content and antioxidant capacity in some medicinal herbs cultivated in Iran. Bot Serb 2012; 36: 117-22.

22. Choung MG, Hwang YS, Lee MS, Lee J, Kang ST, Jun TH. Comparison of extraction and isolation efficiency of catechins and 
caffeine from green tea leaves using different solvent systems. J Food Sci Tech 2014; 49: 1572-8.

23. Gölükcü M, Toker R, Tokgöz H. Farklı sıcaklık ve sürelerde demlemenin dağ çayının (Sideritis congesta) bazı kalite özellikleri üzerine etkisi. Gida 2014; 39: 155-62.

24. Kesic A, Hodzic Z, Crnkic A, Saletovic M, Catovic B. Bioavailability of antioxidants from tea infusions with honey addition. HealthMED 2010; 4: 111-5.
25. Rusaczonek A, Swiderski F, Waszkiewicz-Robak B. Antioxidant properties of tea and herbal infusions - A Short. Pol. J Food Nutr Sci 2010; 60:33-5.

26. Pereira C, Barros L, Vilas-Boas M, Ferreira IC. Potentiating effects of honey on antioxidant properties of lemon-flavoured black tea. Int J Food Sci Nutr 2013; 64:230-4.

27. Ahmed N, Sutcliffe A, Tipper C. Feasibility study: honey for treatment of cough in children. Pediatr Rep 2013; 5: 31-4. 